\title{
SEXUALIDADE, BRINCADEIRA E ESCOLA NO PROCESSO DE NORMALIZAÇÃO DA INFÂNCIA
}

Luan Carpes Barros Cassal ${ }^{\mathrm{i}}$

Cristiana de França Chiaradiai

\begin{abstract}
Resumo: Nos últimos anos, questões sobre infância, escola, sexualidade e gênero estão na mira de variadas proposições do Estado. Assim, este artigo propõe colocar em análise o processo de normalização das subjetividades na infância através da regulação da masturbação no espaço escolar. A construção da sexualidade das crianças, através de brincadeiras e regras, está atrelada a uma relação de gênero tradicional. Além disso, a masturbação é negada como um ato lúdico de prazer para a criança conhecer seu corpo, principalmente na escola. Porém, a tentativa de proibição de assuntos e práticas de construção do corpo e do prazer, mais do que reprimir, insiste em criar modos normalizados de existência. Assim, ao investigarmos relações entre sexualidade, infância e escola, propomos colocar em análise as proibições estabelecidas entre tais termos e a masturbação.
\end{abstract}

Palavras-chave: Brincadeira, sexualidade, masturbação, escola, infância.

Abstract: In the last years, questions about childhood, school, sexuality and gender are subjects of interest of several actions of the public power. Thus, this article proposes to analyze the process of normalization of subjectivities in childhood through the regulation of masturbation in the schools. The construction of children's sexuality, through play and rules, is associated with a traditional gender relationship. In addition, masturbation is denied as a playful act of pleasure for the child to know his body, especially in school. But the attempt to ban questions and practices about bodies and pleasures, rather than repressing something, insists on creating standardized modes of existence. Thus, when investigating the relations between sexuality, childhood and school, we propose to analyze the prohibitions established between such terms and masturbation.

Key Words: Child's play, sexuality, masturbation, school, childhood.

\section{Introdução}

Em 2016, um deputado propôs um polêmico projeto ${ }^{\mathrm{iii}}$ de impedimento ao acesso a sites gratuitos de pornografia. Tal preocupação foi justificada no projeto de lei pelo aumento de supostos viciados em masturbação, por conta de sua disponibilidade, o que produziria dificuldades nas práticas sexuais com outras pessoas. Mesmo sem apresentar dados estatísticos e estudos que correlacionem masturbação, juventude e pornografia, o deputado assegurou ${ }^{\text {iv }}$ que o projeto visa proteger apenas crianças e não interferirá na vida dos adultos. Questões surgiram nas redes sociais ${ }^{\mathrm{v}}$, de internautas preocupados com tal proposta. Enquanto a Câmara dos Deputados tenta ocupar-se da masturbação através de regulações legais repressivos, os relatos sobre masturbação infantil nas escolas continuam a emergir, aparentemente alheios a tal disputa. De fato, nenhuma novidade no interesse pelo onanismo infantil; como Gondra (2015) indica, 
médicos brasileiros propunham manuais de saúde sexual que proibiam a masturbação já no século XIX, com orientações para famílias e profissionais da educação. O referido projeto de lei apenas apresenta-se como um manual com nova roupagem e características do tempo presente.

Assim, as situações que envolvem manifestações sexuais infantis e o espaço escolar são confrontadas por professoras e professores, discutidas por profissionais de saúde, regulada por legisladores. Mas, afinal, o que tanto incomoda? A que serve a masturbação, por que se tenta tanto erradicá-la, e por que não se consegue?

Entendemos que este debate se insere num momento político-educacional delicado onde conquistas referentes ao respeito a diversidade sexual e de gênero foram gradativamente sendo excluídas do espaço escolar. A retirada e exclusão do Projeto Escola Sem Homofobia das escolas em 2011 é o marco deste retrocesso. Outros espaços foram perdidos com a retirada dos itens sobre diversidade sexual e de gênero do último Plano Nacional de Educação e a exclusão da Orientação Sexual como um dos temas transversais do currículo escolar. (NASCIMENTO e CHIARADIA, 2017)

Entendemos que estamos entrando num momento delicado no que se refere as questões sexuais nas escolas, na medida que existe o projeto de lei no 193 de 2016 que tramita no Senado e visa proibir em sala de aula discursos rotulados como ideologia de gênero - ou seja, a abordagem de qualquer discussão do corpo para além de um viés binário e biologizante. Tentam impedir que a escola eduque seus alunos com relação a sexualidade, pois reivindicam que é apenas um direito dos pais esta função, e ainda ignoram quaisquer outros encontros e espaços de experimentação e reflexão para as crianças. "A reivindicação é por um modelo de sexualidade moral, no qual os processos de conhecimento e discussão da vida sexual devem ser dominados apenas pela família, garantindo, desse modo, a aceitação deste domínio e a duplicação das práticas vivenciadas no círculo intrafamiliar, consideradas como ideais e como a única possibilidade" (NASCIMENTO e CHIARADIA, 2017, p.109).

A partir dessas pistas, o presente texto tratará, inicialmente, da construção da noção de infância e a regulação dos corpos infantis. Em seguida, abordará o papel da brincadeira na infância, para dialogarmos com as questões de masturbação e a escola em uma perspectiva lúdica. Encerra-se com perguntas que, mais do que trazer prescrições, podem servir como questionamentos a serem feitos por profissionais em seus campos de atuação. Assim, ao investigarmos relações entre sexualidade, infância e escola, propomos colocar em análise as proibições estabelecidas entre tais termos e a masturbação.

\section{Instituindo a infância}

À ideia mais ou menos estabelecida de que todas e todos os seres humanos passam por um processo de desenvolvimento linear - infância, adolescência, idade adulta e velhice -, as forças do presente indicam rasgos, pois nenhuma destas categorias é imanente ao homem.

No contemporâneo, esquecemo-nos disso e nos relacionamos com as pessoas a partir da chamada etapa de desenvolvimento. Esta categorização explicita o que condiz a cada categoria e assim, define espaços (escolas, parques ou asilos) e produtos (comidas, roupas, brinquedos e filmes) para cada uma delas. Há uma demarcação de espaços e produtos indicados e separados para cada idade, assim como comportamentos esperados. Mais ainda, a psicologia moderna tem papel importante na construção da ideia hegemônica de um tempo linear e por etapas da vida humana: 
Sintetizando essa discussão, é necessário destacar que a característica marcante das teorias do desenvolvimento, do século XIX em diante, é se constituírem como saberes que engendram conceitos universalizantes e abordagens teleológicas que demarcam a natureza e o lugar social dos sujeitos, segundo estágios ou etapas unidirecionais de desenvolvimento, ou segundo sua idade cronológica. [...] Supõe-se, assim, que a infância deve ser vista como mero estado de passagem, precário e efêmero, que caminha para sua resolução posterior na idade adulta, por meio da acumulação de experiências e conhecimento. A linearidade do tempo cronológico autoriza uma compreensão da infância que lhe atribui uma qualidade de menoridade e, consequentemente, sua relativa desqualificação como estado transitório, inacabado e imperfeito. (JOBIM E SOUZA, 1996, p.44).

Há uma categórica recomendação de que, para que se tenha uma vida saudável, o melhor é que isto seja respeitado, pois pode haver consequências nefastas caso se negligencie estas recomendações. Sem perceber, aceitamos este processo de normalização ${ }^{\text {vi }}$ instituído e perdemos o foco no sujeito a frente. Isto acontece mais fortemente com as crianças, que são compreendidas como sujeitos que devem ser protegidos e pelos quais se deve falar e agir. Proteção, que outorga ao adulto as necessidades e desejos, retirando-lhes o estatuto de ator social, e, concomitantemente, delegando uma responsabilidade sobre a experiência presente da criança e os possíveis caminhos que seguirá no futuro. Como analisa o filósofo Michel Foucault (2010, p. 221), no século XIX inúmeros documentos médicos e pedagógicos estabelecem que "Os pais têm de cuidar dos filhos, os pais têm de tomar conta dos filhos, nos dois sentidos: impedir que morram e, claro, vigiá-los e, ao mesmo tempo, educá-los. A vida futura das crianças está nas mãos dos pais". É aí que crianças são entendidas como a chave para o futuro; a escola, seu caminho de formação e, sua família, a guardiã.

Porém, a infância, mais do que um processo natural, é uma instituição com história. Ariès (1978) realizou um mapeamento do surgimento do conceito de infância no Ocidente; o autor relata que, na Idade Média europeia ${ }^{\text {vii }}$, pouca distinção se fazia entre infantes e adultos. A partir do momento em que os pequenos começavam a caminhar, integravam-se no mundo adulto - em seus jogos, linguagens e atividades. Os corpos poderiam se misturar com toques, olhares e

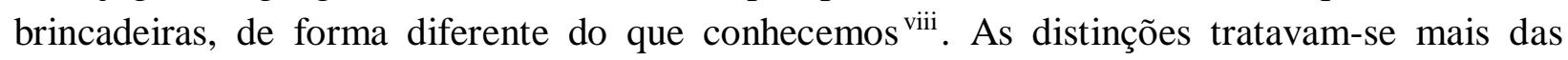
capacidades e possibilidades físicas e mentais do que a compreensão de uma categoria de sujeitos absolutamente diferente por conta da idade, como temos hoje. Ao mesmo tempo, a mortalidade infantil era muito maior, o que diferenciava a relação de tempo e de apego às crianças.

Assim como a infância, a escola também é uma instituição com história. Atualmente, se estrutura numa hierarquização do conhecimento instaurada a partir da concepção de desenvolvimento. Há idade para entrar na escola como também para se sair dela, há idade para se adquirir um determinado conhecimento e não outro. Parece que esquecemos que a escola nem sempre se sustentou neste modelo, pois o processo de escolarização também era bastante diferente, de acordo Ariès (1978). Os espaços de educação escolar, como hoje conhecemos, estavam limitados a alguns monastérios, que realizavam cópias e traduções de textos importantes. A importância estava na repetição da tradição. A aprendizagem com frequência se 
dava nas poucas cidades, na casa de instrutores que repetiam lições de obras clássicas. Vale destacar que as turmas não tinham distinção de idade ou nível de aprendizagem.

É com a produção de um 'sentimento de infância' que tal situação muda, fazendo com que cada vez mais, descreve-se as crianças como criaturas absolutamente diferentes dos adultos, que precisariam de linguagem e roupas específicas. (ARIÈS, 1978). A emergência da escola moderna, pretensamente básica e universal, está associada à ideia de uma infância comum, com certas normas de desenvolvimento. Mais especificamente, aposta em uma ideia de maturação, conforme nos explica Solange Jobim e Souza (1996, p.42): "As teorias de Freud e Piaget constituem exemplos que se enquadram dentro do paradigma evolucionista, em que os atributos e funções psicológicos são passíveis de mudanças dentro de uma sequenciação hierarquizada".

Foucault $(1987,1988,1999)$ conta que o período histórico de advento da modernidade foi marcado pela organização dos Estados-Nação na Europa, bem como pela migração da população das cidades para o campo. Os estados nacionais foram estabelecidos com base em um território específico, na população que ali habita e nos valores culturais tomados como hegemônicos (narrativas, lendas, língua, cultura, história, brasões, dentre outros elementos representativos). O principal bem das nações é, de acordo com o autor, a sua população, que deveria tornar-se cada vez maior e mais saudável para, assim, aumentar a riqueza e a potência do próprio país. Com isso, cresce a preocupação com a infância, entendida como um investimento político e econômico para o futuro do corpo individual e do corpo populacional. A partir daí se dá a universalização da ideia de humano, enquanto sujeito que produz riqueza e consome bens. Esse humano que deve ser estudado em suas leis gerais de funcionamento e formado do modo mais eficiente possível. Dessa forma, não por acaso, a família nuclear é organizada e designada para o cuidado das gerações futuras pelos saberes médico-científicos. Estes, junto com a escola, tornam-se estratégias de produção controlada de subjetividades, "[...] cuja matriz é a situação histórica e social do homem moderno, submerso nas exigências de um ideal de sujeito produtivo e consumidor" (JOBIM E SOUZA, 1996, p.46).

Na sociedade disciplinar discutida por Foucault (1987, 2010), as escolas, os hospitais e as prisões se espalham por todo o território e todo o corpo social - todas as pessoas poderiam e/ou deveriam passar por elas - e se especializam no controle da rotina de funcionamento, a fim de produzir corpos docilizados. Para sua produção, há um maior controle da população através da produção de dados sobre categorias específicas com orientações e regras de um chamado bem viver. Mais ainda, os sistemas médicos e jurídicos buscam dar conta das situações que escapam aos padrões. Se o foco dos investimentos do poder na Idade Média era nos corpos e nas vidas que não cumpriam as regras legais e científicas, a partir do século XVIII ganha força uma série de estratégias que se preocupam com os comportamentos que destoam à norma. "Portanto, análise do território em seus elementos mais pormenorizados; organização, através desse território assim analisado, de um poder contínuo [...] Era um poder que era contínuo também em seu exercício, e não apenas em sua pirâmide hierárquica, já que a vigilância deveria ser exercida sem nenhuma interrupção. [...] Não se trata de uma exclusão, trata-se de uma quarentena. Não se trata de expulsar, trata-se ao contrário de estabelecer, de fixar, de atribuir um lugar, de definir 
presenças, e presenças controladas. Não rejeição, mas inclusão” (FOUCAULT, 2010, p.39).

Quanto mais expressões desviantes, mais se justificam as instituições disciplinares, que tentam regular - mas não eliminam - as expressões de diferença.

Artimanhas biopolíticas de controle social vão se instaurando. Deste modo, tudo e todos devem ser enquadrados e aqueles que não condizerem com isto serão os sujeitos fora da norma, os socialmente entendidos como anormais.

\section{Sexualidade para governo de um projeto de infância}

Por que há tanta resistência às práticas de masturbação infantil no geral? Como explica Foucault (1979, 1988, 2010), no início do século XVII, pouco segredo se fazia em torno das práticas sexuais. As proibições que vigoravam tinham o sentido de cumprimento da lei, representação ora do poder judiciário, ora do poder monárquico, ora do poder pastoral. Os séculos seguintes indicam inúmeros esforços para controle e organização dos corpos, das relações e dos prazeres. Uma aparente repressão, que se revela incitação difusa de discursos, multiplicação das formas de exercício do poder, doutrinamento das possibilidades de prazer. Constrói-se uma ciência que fundamenta o humano na sexualidade, enquanto essência do indivíduo e futuro da população.

Um dispositivo da sexualidade toma forma, que enlaça corpos, saberes, práticas, linguagens, arquiteturas, políticas, modos de gestão e subjetividades. A sexualidade é, assim, ponto de encontro e investimento de um poder que se exerce sobre a vida, para dela extrair o máximo de potência e eficiência - um biopoder. É a busca do corpo ideal, para hoje no indivíduo e para amanhã na população (FOUCAULT, 1979, 1987, 1988).

Essa história contada por Foucault remonta a pelo menos 300 anos atrás. Entretanto, é um processo extremamente atual, posto que o regime de poder sobre a vida estabelece modos como construímos e experimentamos os corpos:

Tudo, afinal, como se acredita, começa na origem, na infância, espaço a ser trabalhado, redefinido, medicalizado e modelado. Seguindo os passos de Foucault, ficamos sabendo que a sexualidade infantil passa a ser controlada tanto pela prática de confissão (isto é, pela obrigação de ser obediente e dizer a verdade a uma autoridade, prática que se difunde progressivamente desde o cristianismo) quanto pela organização meticulosa dos espaços. Entre os séculos XVII e XVIII, no mundo ocidental, acredita-se que os espaços devem ser cuidadosamente organizados, no interior dos estabelecimentos de formação escolar cristã e católica, dos bancos, carteiras e mesas na sala de aula à supressão dos lugares escuros. Tudo nos estabelecimentos escolares, colégios e internato deve ser rigorosamente ordenado, pois tudo designa os perigos desse corpo de prazer. Menos discursos incandescentes, melhor disposição dos dispositivos materiais. Como se as coisas, para além das palavras, pudessem controlar as almas e os corpos e definir o desejo, observa o filósofo historiador. (RAGO, 2015, p. 244). 
As manifestações do poder no funcionamento das sexualidades e dos gêneros se fazem desde antes do nascimento. Butler (2010) e Louro (2004) explicam tal questão. Os primeiros contatos com a imagem do bebê no exame de ultrassom (ou a materialidade do corpo no parto) produzem expressões como 'é uma menina' ou 'é um menino' e, assim, formalizam uma trajetória pronta para cada corpo. São mais intervenções pelo saber médico (da demarcação de um sexo definido) que reverberam em demarcações jurídicas (do registro legal em um sexo específico).

Desde os primeiros dias de vida lhe será apresentado os desejos e sonhos de seus ascendentes quanto a pessoa que esperam que se torne, pois o nome, a decoração do quarto e os brinquedos já terão indicativos do que se espera. Será a partir do nascimento que a criança vai percebendo estas e outras expectativas sobre si. O desejo da construção de si e dos encontros com os outros tornam-se pacotes de agência de turismo: pré-programados, supostamente imunes às surpresas e tempestades. Para cada genitália, uma construção do corpo, dos comportamentos e dos desejos. Em outras palavras: "Uma matriz heterossexual delimita os padrões a serem seguidos e, paradoxalmente, fornece a pauta para as transgressões. É em referência a ela que se fazem não apenas os corpos que se conformam às regras de gênero e sexuais, mas também aos corpos que as subvertem" (LOURO, 2004, p. 17).

Nessa relação, quando necessário, o corpo é corrigido para que se adéque à padronização de aparência da genitália. Feminino e masculino tornam-se marcas que fundam o sujeito; para a organização médico-científica e jurídica, não haveria possibilidade para sua existência fora dessa lógica, e não se reconheceria como humano aquele que desse sistema escape. "Investidas de poder e obstinação, essas normas estabelecem os limites do que será considerado uma formação inteligível do sujeito dentro de determinado esquema histórico das coisas. Não há criação de si (poiesis) fora de um modo de subjetivação (assujettisement) e, portanto, não há criação de si fora das normas que orquestram as formas possíveis que o sujeito deve assumir" (BUTLER, 2015, p.29, grifos no original). Isso porque a construção do humano implica sempre na marcação de fronteira para um espaço exterior a partir de condições anteriores à emergência do sujeito ${ }^{\text {ix }}$. A norma é produzida pela delimitação de um 'outro', estrangeiro, anormal; e em relação ao qual nos produzimos incessantemente. O desenrolar da história esperado é a tentativa de evitar ou fugir do lugar transgressor. A expectativa sobre o sexo se materializa na performatividade dos corpos e de seus prazeres e desejos (BUTLER, 2010, LOURO, 2004).

Nesse sentido, Butler (2010; 2015) e Louro (2004) corroboram com a leitura de que a fabricação dos corpos e prazeres demanda um esforço constante do regime de poder, que passa inclusive pela delimitação de brinquedos e comportamentos designados como exclusivos de um gênero ou de outro. $\mathrm{O}$ aparato cultural instituído oferece os modelos e recursos com os quais nos relacionamos e, de nós, exigem, repetição. Após o ritual de declamação do sexo/gênero, a norma torna-se citada a cada momento em que se fala, se veste, se movimenta e se escolhe caminhos. $\mathrm{O}$ poder constrói uma ficção de naturalidade; entretanto, só pode se estabelecer e manter através das reiteradas repetições. Assim, em nome desta proteção, a escola se justifica no controle destas subjetividades para se enquadrarem num modelo desejado e normatizado. 


\section{Produzindo e normalizando a criança}

O brinquedo, mesmo quando não imita os instrumentos dos adultos, é confronto, e, na verdade, não tanto da criança com os adultos, mas destes com a criança. Pois quem senão o adulto fornece primeiramente à criança os seus brinquedos? (BENJAMIN, 2009, p. 96).

Ao fazer um registro da história da modernidade, o filósofo Walter Benjamin (2012, 2015) mostrou-se interessado pelas reminiscências da infância no começo do século XX e as transformações que observava na paisagem, na cidade, nos objetos, nas rotinas e nos modos de contar histórias. Seus textos destacam, por exemplo, a transformação dos brinquedos e vestimentas de crianças com o processo de industrialização: de versões reduzidas (e sobras) dos objetos e roupas dos adultos, ganharam contornos, formatos, cores e estilos muito específicos. A introdução de novos materiais e processos de fabricação possibilitaram rápidas mudanças nos objetos e no perfil de consumo. Reduziu-se a duração e aumentou-se a necessidade. Os brinquedos, as roupas e os jogos de crianças tornaram-se absolutamente específicos e diferentes dos adultos: um mundo a parte. Nada deveria aproximar nós e eles:

Com isso as crianças formam para si seu mundo de coisas, um pequeno no grande, elas mesmas. Seria preciso ter em mira as normas desse pequeno mundo de coisas, se se quer criar deliberadamente para as crianças e não se prefere deixar a atividade própria, com tudo àquilo que é nela requisito e instrumento, encontrar por si só o caminho que conduz a elas. (BENJAMIN, 2012, p. 17).

Este universo infantil que vai se construindo, também vai se constituindo numa tentativa de aprisionamento destes sujeitos, na medida que elas são obrigadas a participarem numa lógica cuja as regras são definidas apenas pelos adultos, a chamada lógica adultocêntrica. Segundo, Kramer o adultocentrismo é uma "abordagem da infância e do mundo social e cultural em que se insere a partir do ponto de vista do adulto" (2005, p.129). Deste modo, a definição do que é brinquedo ou não e como os mesmos devem ser manuseados serão definidos, a priori, pelos adultos que a cercam. Por outro lado, as crianças se relacionam com os objetos que encontram, constroem mundos possíveis e interrogam as relações que os adultos anteriormente estabeleceram:

A criança está sempre pronta para criar outros sentidos para os objetos que possuem significados fixados pela cultura dominante, ultrapassando o sentido único que as coisas novas tendem a adquirir. [...] A criança conhece o mundo enquanto cria, e, ao criar o mundo, ela nos revela a verdade sempre provisória da realidade em que se encontra. (JOBIM E SOUZA, 1996, p.49).

A importância da brincadeira no desenvolvimento (visto como linear ou não) é corroborado no Estatuto da Criança e do Adolescente - ECA, em seu artigo 16, inciso IV coloca que "o brincar, praticar esportes e divertir-se" (BRASIL, 1990) são aspectos do direito a liberdade que a criança e o adolescente possuem. Apesar de ser inscrito como um direito, o mesmo é limitado pelo adulto, que costuma impedir a liberdade da criança de ampliar seu 
repertório lúdico vivencial, demarcando o que é passível de ser experienciado por faixa de idade e definição de gênero.

$\mathrm{O}$ adulto, sem perceber, repete os padrões sociais que muitas vezes censura. Não é incomum a crítica da relação de dominação ou de dependência que ainda existem nas relações entre as pessoas e principalmente entre os casais, em que há papéis sociais estanques e que aprisionam as pessoas pela potencialidade limitada de suas ações. Porém, também, não é incomum se criar cotidianos lúdicos para as crianças que mantenham essas relações " [...] a escola está 'fora do seu tempo' frente aos papéis de gênero. Geralmente as estereotipias que discriminam o homem e a mulher como desiguais, são tradicionalmente reforçadas no ambiente escolar, podendo-se encontrar atitudes de forte machismo, mesmo nas mulheres" (GUIMARÃES, 1995, p.17-8).

Nas brincadeiras das crianças, a perpetuação destas relações cristalizadas em relação aos gêneros é recorrente, pois há adultos que não deixam as crianças brincarem com determinados objetos, associando seu manuseio a diversas fantasias sobre práticas corporais e sexuais futuras daqueles sujeitos. Ainda se vê uma prática lúdica que identifica “[...] o universo doméstico (em particular para os brinquedos destinados às meninas) o universo do automóvel, do transporte (para os meninos)" (BROUGĖRE, 2001, p.42). Como parte de um desejo por ensinar os comportamentos definidos e delimitados por gênero, a menina não é estimulada a brincar com automóveis e o menino, com bonecas. Inclusive, as crianças são frequentemente rotuladas de problemáticas se em algum momento se negam a usar os brinquedos da forma estabelecida ou quando arriscam a manusear o que é entendido como restrito ao gênero oposto. Essas falas surgem associadas a uma ideia de que qualquer ato da criança indica ou marca um suposto perigo de transgredir as normas sobre gênero e sexualidade - um processo onde, de acordo com Foucault (2010, p. 264): “[...] vemos se definir aí uma nova posição da criança em relação à prática psiquiátrica. Trata-se de pôr em continuidade, ou antes, de pôr em imobilidade a vida em torno da infância”.

Porém, para ampliar as possibilidades futuras destas pessoas é importante ampliar o repertório vivencial destas crianças, permitindo que elas se exercitem através das brincadeiras e dos jogos, não os limitando a um universo pré-definido.

[...] são associadas, por tradição cultural, representações privilegiadas do masculino e do feminino. O universo do brinquedo feminino é nesse aspecto, muito interessante por tratar-se daquele considerado como tal pela sociedade, pelas crianças, pelos pais, pelos comerciantes, independentemente das brincadeiras efetivas mais aberta à diversidade: privilegia o espaço familiar da casa, o universo 'feminino' tradicional em detrimento do externo, do universo do trabalho. (BROUGÈRE, 2001, p.43).

Para as meninas compreenderem que há outros papéis, além do de ser mãe e de administradora doméstica é importante que brinquem com diversos objetos: bolas de diferentes tipos, carros, computadores, ferramentas em geral, livros diversos e objetos associados a diferentes profissões (como estetoscópio e maleta de executivo), entre outros. O mesmo para os meninos que devem poder brincar com os utensílios domésticos que estimulem sua independência diária, bem como com bonecos variados que lhes permitam exercitar as relações com outras pessoas e a exercerem o cuidado e a interação com pessoas de menor idade que ele. 
De fato, na brincadeira, as crianças tentam entender o mundo no qual estão inseridas; com um repertório variado, amplia-se também possíveis questões e respostas aos problemas que o sujeito depara no seu caminhar.

Nestas atividades a criança cria, imagina e percebe melhor o seu entorno referente aquelas situações lúdicas, ela fica mais perceptiva e mais crítica aos papéis sociais relativos ao gênero. Não se pode esquecer que a criança se exercita socialmente através de suas brincadeiras e que os objetos são convites e instrumentos fundamentais para esse exercício.

Quando a criança lida com a linguagem de forma lúdica ela rompe com as formas fossilizadas e cristalizadas de seu uso cotidiano. Dessa forma, podemos dizer que as crianças usam a linguagem para protestar contra os limites da realidade, transgredindo-a, ao mesmo tempo em que protegem a realidade contra a tirania da linguagem. (JOBIM E SOUZA, 1996, p.48).

Para que as crianças tenham estimulado seu desejo de dirigir, por exemplo, é importante este ato lúdico com os automóveis. Assim, as habilidades para ser motorista seriam estimuladas desde pequenos para os dois sexos. Como também, o ato de cuidar e educar uma criança é estimulado na medida que esta atitude lúdica é permitida para ambos com o manuseio de bonecos bebês. Se, por um lado, tais estímulos não são determinantes, por outro ajudam a estabelecer algumas experiências como parte do mundo real e como ações compartilháveis - não apenas fantasias.

Posturas mais coerentes com a diversidade de papéis de gênero já são relatadas no interior dos lares das crianças. Imagine, há um tempo atrás, um pai com suas duas filhas (de seis e nove anos) disse que comprava carrinhos para a sua caçula: afinal, ela gostava de brincar com eles. Este pai considerou que esta ação traz informações importantes sobre o papel social de cada gênero. Com esta atitude, ele profere que as meninas têm em seu futuro a possibilidade (o que é diferente de obrigatoriedade) de serem motoristas, pilotos, mecânicas ou engenheiras de automóveis. Ele abre um leque de atividades automobilísticas além do simples mover-se motorizado, ampliando as possibilidades de habilidades futuras à menina, na medida em que traz uma representação associada ao masculino para o universo feminino. O automóvel deixa de ser um objeto para brincadeiras apenas dos meninos, quebrando uma compreensão que limita o universo do brinquedo feminino ao espaço familiar da casa, como bonecos e objetos de cozinha. $\mathrm{E}$, mais ainda, as crianças podem inventar suas próprias narrativas com o brinquedo. $\mathrm{O}$ carro pode virar foguete, barco, veículo para uma viagem pelo mundo ou para circulação na cidade.

Aumentar o repertório vivencial das crianças através de suas brincadeiras é fundamental para a ampliação dos papéis de cada gênero, pois este exercício facilitará a percepção do seu entorno e com isto criaria mais subsídios para elas discutirem e modificarem o status quo, pois "[...] manipular brinquedos remete, entre outras coisas, a manipular significações culturais originadas numa determinada sociedade.”. (BROUGÈRE, 2001, p. 42).

Nesta lógica restritiva do lúdico, aos meninos é comumente permitido manusear bonecos que sejam associados a guerra ou a profissões tradicionalmente masculinas como soldado, mecânico, bombeiro ou médico. Há um impedimento para os meninos de manusearem bonecos bebês ou bonecos mais familiarizados com o seu dia a dia, pela compreensão que limita estes objetos a um universo feminino. Inclusive, erroneamente se associa este ato lúdico dos garotos a 
um suposto desejo homossexual que estaria a se manifestar. Em outras palavras, como se qualquer manifestação fora das normas seria um indicativo de uma suposta homossexualidade latente. E aí, faz-se necessário posicionar - um menino brincar de bonecas nada mais é do que uma brincadeira de bonecas.

Por outro lado, mesmo reprimir um menino no uso de bonecos bebês e brinquedos entendidos como femininos, não impede que a fantasia de brincadeira de cuidado aconteça no encontro com quaisquer outros objetos. Como nos lembra Jobim e Souza (1996, p. 50) "A imaginação é um processo novo que surge como mediador do conflito entre o desejo e a frustração com que depara a criança por não poder concretizá-lo".

A brincadeira é fundamental no processo de compreensão e elaboração do mundo. A esse respeito, Walter Benjamin destaca que "A essência do brincar não é um 'fazer como se', mas um 'fazer sempre de novo', transformação da experiência mais comovente em hábito. [...] O hábito entra na vida como brincadeira" (BENJAMIN, 2009, p. 102). Os brinquedos criam a possibilidade de conhecer e construir o mundo. Como aponta Vygotsky (1998), são modos das crianças experimentarem a relação entre real e imaginário e, com isso, estimularem a aprendizagem cada vez mais, onde podem compreender as regras, as expectativas, a passagem do tempo e as relações.

Ou seja, jogos e brincadeiras podem ampliar o repertório vivencial infantil, mas não determinam comportamentos futuros, seja em termos de gênero ou de sexualidade. Por exemplo, apesar da forte repetição para que meninas brinquem com bonecas e prendas domésticas e, ainda que a imensa maioria das mulheres passe por essa experiência, mesmo assim produzem diferentes relações com essas tarefas ditas femininas. A criança não é uma folha de papel em branco na qual se preenchem procedimentos: é, de fato, um corpo inquieto, pleno de força e de conexões, e que faz aparecerem os nossos limites sociais. Ao brincar, experimenta a matéria, as representações, as regras e as relações estabelecidas. E, assim, se apropria e aprende sobre si e seu mundo.

Além de se definir os objetos e seus usos, estabelecendo o que podem ou não ser manuseados pelas crianças, há uma limitação do uso do seu corpo nestas atividades. Um limitador do uso do corpo aparece nas brincadeiras quando o adulto entende que há uma conotação sexual na atividade. Ora, mas a identificação de qualquer brincadeira vem de que lugar, em qual repertório? Ou seja, a marcação de uma ação como sexual passa pela fala de um adulto. As crianças vão aprender conosco os significados socialmente estabelecidos de um movimento, de um jogo, de uma roupa, de um encontro.

Padrões de condutas tradicionais serão esperados para que uma brincadeira seja considerada saudável, principalmente no que se refere a sexualidade. Para isto, uma perpetuação de papéis masculinos e femininos devem ser explicitados no evento.

Devem ser explicitados com uma certa discrição. Assim, a simulação de um namoro deve se limitar a um jogo sem muitos toques físicos e os atos não devem insinuar ao adulto a aproximação de uma relação sexual, pois uma percepção sexualizada da criança é algo que deve ser excluído deste cenário. No palco lúdico, experiências sexualizadas que lembrem atos considerados de adultos ou de adolescentes são proibidos às crianças. Do mesmo modo, a masturbação não deve aparecer nas brincadeiras, pois é algo pouco aceito como ato lúdico infantil. 


\section{Masturbação como uma brincadeira com seu próprio corpo}

Chega a hora da escola, e com ela um novo sistema disciplinar de regras ${ }^{\mathrm{x}}$. As educadoras Bacca, Pey e Sá (2004, p. 89) explicam que, se até certo momento histórico, a escola era para poucos, mas todos eram sujeitos com diferentes saberes, nos séculos XVIII e XIX a escola se estabelece no lugar de instituição de saber, e marca quem está fora dela como aquele que não sabe. A escola produz, em primeiro lugar, alunos - e, consequentemente, marca aqueles que não o são:

Não é a eficácia do aluno tirar nota alta. É a eficácia do aluno se construir enquanto aluno, enquanto escolar [...]. Isso tudo vai construindo-os como alunos, dóceis, submissos, aceitando tudo com normalidade [...]. Justamente por serem construídos como tal que a maioria das subjetividades se reafirma com a disciplina e desejam esses procedimentos disciplinares. (BACCA; PEY; SÁ, 2004, p. 89).

$\mathrm{Na}$ escola, funciona a disciplina - regulação dos corpos através dos detalhes do tempo e do espaço. Cada local tem sua função definida e cada momento tem uma atividade a ser cumprida. Assim, a brincadeira e o brinquedo têm hora e lugar definidos - e cada vez mais reduzidos com o desenrolar do percurso de escolarização. Entretanto, as crianças inquietas insistem em desobedecer. Às vezes, provocam os colegas; criam jogos em sala com olhares, gritos, bilhetes, bolinhas de papel, caretas, implicâncias. Desestabilizam a proposta, e as educadoras e os educadores precisam manejar os impasses.

Por vezes, as crianças produzem modos sutis de burlar as regras. Podemos retirar todos os objetos de perto, separar as crianças e direcionar tarefas específicas. Ainda assim, há muitos mundos à disposição. Por um lado, a imaginação e a fantasia estão disponíveis, por outro, de forma ainda mais concreta, o corpo pode tornar-se um imenso parque de diversões. E, dentre essas possibilidades de brincadeira autossuficiente, que pouco passa pela negociação, vamos destacar as práticas masturbatórias - aqui entendidas como atos de auto-estimulação corporal, frequentemente genital, pela própria criança, possivelmente com experiência de prazer. A masturbação infantil é uma prática considerada por muitos como escandalosa e, ainda assim, assustadoramente recorrente e comum. $\square \square$ Atual e, mesmo assim, causa preocupação há séculos:

Parece-me pois que a sexualidade da criança e do adolescente é posta como problema no decorrer do século XVIII. Essa sexualidade é posta inicialmente sob sua forma não relacional, isto é, é posto em primeiro lugar o problema do autoerotismo e da masturbação; masturbação que é perseguida, masturbação que é valorizada como um perigo maior. A partir desse momento, os corpos, os gestos, as atitudes, as caras, os traços da fisionomia, as camas, os lençóis, as manchas, tudo isso é posto sob vigilância. (FOUCAULT, 2010, p. 231).

Três séculos de cruzadas, intervenções e movimentos contra a masturbação não conseguiram eliminar tal comportamento. Pelo contrário: como aponta Foucault $(1988 ; 2010)$, apenas aumenta-se a produção de discursos (orais e escritos, informais e acadêmicos) sobre o assunto. Cada vez mais se fala sobre a sexualidade infantil e, especificamente, a masturbação. As 
ciências investigam, registram e analisam tal fenômeno, sem conseguir impedi-lo. Um fracasso constante, que parece quase intencional.

Ora, será que a masturbação, problema recorrente há muitas e muitas gerações de profissionais, caberá na/à escola? Deveríamos falar dela, ou impedi-la, ou ignorá-la? Ora, quando crianças e adolescentes adentram o espaço escolar, todos os seus comportamentos estão sob observação e, por conta deles, são produzidas respostas. Orientações, premiações, sanções. Qualquer comportamento que passe desapercebido ao ser feito publicamente significa que é autorizado. Por exemplo, algumas crianças que brincam de pegar no pátio, na hora do recreio. Se nada é dito, significa que não há problema algum. Serão chamadas atenção, porém, se fizerem a mesma brincadeira no meio da sala de aula; ou então, caso haja violência nesta atividade.

Outro exemplo. Em alguns contextos, as crianças podem comer lanches, doces ou beber água em sala de aula. Apenas tornará motivo de uma produção discursiva por parte do adulto quando for algo proibido.

Neste sentido, algumas brincadeiras são censuradas na coletividade e vão se restringindo em lugares distantes dos olhares dos adultos. Veja: o silêncio e o afastamento não se dão por algo de essencial na brincadeira ou nas próprias crianças, mas pelas respostas que ensinamos cada vez que há alguma manifestação considerada, digamos, 'inadequada'.

O que fazer então com a masturbação infantil? Há uma função pedagógica em discutir, pactuar e sustentar as combinações para convivência na sala de aula e nos espaços públicos. Mais do que uma proibição, trata-se de colocar em cena, sem medo, através de uma discussão: práticas de prazer cabem na escola, na frente uns dos outros? Como respeitar os limites dos corpos, pensar sobre a responsabilidade e direitos de seu uso?

A produção intelectual e o aprendizado também podem ser experiências de prazer, alegria e satisfação, para docentes e discentes, como nos lembra Louro (2004). Então, de que forma a descoberta do mundo e do corpo no processo escolar, que tem um tempo muito específico, pode despertar mais interesse do que as práticas masturbatórias?

Há espaços na escola que não são públicos, ou de fácil acesso, especialmente para as pessoas adultas. O canto do corredor, a casa em miniatura, embaixo do banco. Espaços onde os pequenos têm privacidade. Nesses casos, o que faremos? Será que devemos assumir por princípio a vigilância total e absoluta de todos os movimentos das crianças, com adultos presentes ou câmeras? Mais ainda, será possível tal fiscalização, ou apenas produz uma exaustão nos profissionais por ser um processo interminável? Ou impedir o acesso, eliminar as frestas e produzir um espaço absolutamente útil e funcional resolverá o problema? Se a masturbação não produz adoecimento, por que devemos vigiar ininterruptamente para proibi-la?

O desejo de investigar as minúcias do corpo das crianças torna-se uma prática devoradora da infância, de superinvestimento sexualizante dos seus corpos. Quanto mais queremos saber da masturbação infantil através da vigilância, talvez mais a estimulemos, como assunto e como prática. Afinal, qual o interesse de profissionais em observar e investigar ininterruptamente os corpos infantis?

Antes de pretender ter a resposta apaziguadora ou a solução que encerra os conflitos, quer discutir (e desmantelar) a lógica que construiu esse regime, a lógica que justifica a dissimulação, que mantém e fixa as posições de legitimidade e ilegitimidade [...]. Uma tal pedagogia sugere o questionamento, 
a desnaturalização e a incerteza como estratégias férteis e criativas para qualquer dimensão da existência (LOURO, 2004, p. 52).

A masturbação infantil aparece como um problema já previamente formulado e com uma direção única de solução: ou seja, eliminado. Sugerimos, entretanto, mudar a perspectiva e a construção da problemática. Entenda, a noção negativa e problemática da masturbação é aprendida através dos adultos que estão a sua volta, pois estes adultos ainda trazem resquícios da ideia preconizada no século XIX de que a masturbação é um mal que deveria ser extirpado, pois “"o jovem masturbador' será atacado como o produtor de uma espécie degenerada, debilitada, frágil, portadora de um estigma degenerativo" (RAGO, 2015, p. 246).

A masturbação surgiu como um problema destacado e alvo de estratégias específicas no século XVIII - e não antes - como parte da intervenção médica na organização das famílias e dos lares da burguesia então emergente. A partir daí, como conta Foucault (2010), a masturbação foi associada a todo tipo de adoecimentos físico e psíquicos, sem quaisquer evidências. Os manuais médicos perguntavam se os adultos acometidos por enfermidades variadas já tinham se masturbado alguma vez; tendo em vista que a resposta era recorrentemente afirmativa, faziam tal associação. Não era uma precisão médica, mas a intenção de criar estratégias para vigilância constante especialmente dos corpos infantis. Mais ainda, atende à "[...] organização de um espaço familiar restrito e denso; infiltração da sexualidade através de todo esse espaço e investimento desse espaço por controles ou, em todo caso por uma racionalidade médica" (FOUCAULT, 2010, p. 233).

A visão que pregava a repressão das manifestações masturbatórias tratando-as como nocivas não tem mais lugar na produção atual sobre sexualidade. "Hoje, a masturbação não é mais um fantasma, já não assusta ninguém; o discurso médico e, às vezes, o religioso, aliás, passam a defender o prazer sexual como benéfico à saúde, ao corpo e à alma" (RAGO, 2015, p. 254).

Não temos mais produções que sustentem a masturbação como negatividade seja da criança, do adolescente, do adulto ou do idoso ${ }^{\mathrm{xi}}$. Academicamente, ela faz parte sobre o domínio do corpo, não causando nenhum mal à saúde, seja física ou mental, daquele que a pratica. Porém, o que encontramos no interior das escolas é a negação deste preceito, em um esforço no ambiente educativo para suprimir o assunto. Quando uma criança manifesta comportamento masturbatório ou conta de suas experiências, é rapidamente silenciada. Teme-se que estimulem umas às outras, que as famílias façam queixas, que os órgãos de educação reclamem. Assim, fala-se, de muitas formas, que não se deve dizer sobre o assunto. Um grande esforço para silenciar esta prática faz com que se mitifique o tema. Deste modo, a masturbação parece algo indesejado no cotidiano escolar:

a manipulação curiosa e prazerosa dos genitais e as brincadeiras que envolvem contato corporal nas regiões genitais são frequentes nos ciclos iniciais. A intervenção dos educadores nessas situações deve se dar de forma que aponte a inadequação de tal comportamento às normas do convívio escolar, não cabendo a eles condenar ou aprovar essas atitudes, mas sim contextualizá-las. Compete aos educadores compreender, então, que não se trata de aberração que justifique informar os pais. É função da própria escola estabelecer diretamente com seus alunos os limites para o que pode ou não ocorrer dentro dela. A 
convocação dos pais só se justifica quando se tratar de práticas muito recorrentes e que estejam interferindo nas possibilidades de aprendizagem do aluno ou demandem cuidados com sua saúde. Isso pressupõe a intervenção anterior dos educadores com os alunos envolvidos na situação. A convocação não pode substituir a ação junto às crianças e adolescentes e, caso ela ocorra, os alunos devem estar cientes dela. (BRASIL, 1998, p. 300-1).

Assim, o Ministério da Educação, através de suas orientações curriculares, posicionou a masturbação como algo frequente; mas ainda aponta como um comportamento inadequado às normas do convívio escolar e se for recorrente deve ser informado aos pais - ou melhor, aos responsáveis. Neste sentido, pelo exposto, a masturbação não deveria aparecer na escola, seu espaço deveria ser o espaço familiar. Segundo estas orientações, a responsabilidade por estes eventos seria dos responsáveis e não dos educadores. A postura que se encontra no ambiente escolar é a de controle da masturbação. Porém, a masturbação passa pelo domínio do corpo, pelo conhecimento das possibilidades de prazer e de desprazer ${ }^{\text {xii }}$ que se consegue sozinho, passa pelo domínio de si. O indivíduo independente da idade vai testando suas possibilidades corporais, seja nas habilidades físicas, emocionais ou relacionais; experimenta a fantasia e as relações de permitido e proibido. Afinal de contas, como poderíamos configurar um comportamento como recorrente? Uma prática indesejada como a masturbação infantil no ambiente escolar terá uma baixíssima tolerância; será rapidamente marcada como recorrente para ser reprimida. Quando a masturbação se repete, será que os profissionais entendem como um ato que já tornou-se instalado no corpo, como se fosse um adoecimento e, então, há uma busca das causas que fazem repetir?

Ora, devemos considerar o ambiente em que acontece: na discussão aqui em tela, as escolas. Se entendermos a masturbação como uma brincadeira, ela faz parte da construção de hábitos. Mas também é um jogo com a instituição escolar quando se dá em sua área de influência. Veja bem, a intervenção da escola não é no sentido de um problema a ser solucionado, mas como um convite para a interpelação desse Outro que também o constitui: as adultas e os adultos no espaço escolar. A repetição é parte do processo de brincadeira.

Desde pequena, a criança vai apreendendo o que lhe cerca, vai testando seu corpo em relação ao mundo. Quando a criança se movimenta repetindo atividades que lhe dão prazer vai descobrindo partes do seu corpo, a mão, o pé, a boca e inclusive os órgãos sexuais. Para ela, talvez seja só mais uma descoberta das possibilidades corporais que possui. Para ela, quem sabe não haja problema ou maldade neste ato e sim uma ludicidade na ação.

A prática masturbatória pode ser indesejada no espaço escolar. Mas isso não exime-nos, educadoras e educadores, de um posicionamento crítico frente a ela. Mais do que procurar um significado nelas próprias, elas fazem uma convocação, que permitirá discutir corpo, prazer, brincadeiras e regras.

\section{Considerações: $O$ corpo e o lúdico}

Para o adulto, o uso do corpo não possui o lugar instituído de prazer, ele nem deve insinuar esta habilidade. A criança, no seu movimento de experimentação, desafia as regras 
através da masturbação, fazendo de seu corpo um espaço de ludicidade. Em função disso, a escola a reprime.

$\mathrm{Na}$ escola, o corpo infantil deverá ser instrumento de uma produtividade intelectual rígida, cansativa e disciplinarizada que em nada se assemelha ao lúdico de um prazer individual. Atos lúdicos podem ocorrer neste ambiente, mas não são prioridades, devem ser coletivos e previamente programados. Deste modo, a masturbação fere as regras estabelecidas, pois nela a busca de prazer é o seu mote, um prazer individual e independente do que consta a sua volta.

Podemos voltar ao alerta de Foucault (1988), que as proibições em torno da sexualidade e corpo, mais do que repressão, são produções discursivas sobre um assunto e, desse modo, incitam possibilidades. Assim, projetos de leis do legislativo e vetos do executivo, como aqueles que ilustram o início deste texto, assim como práticas profissionais no cotidiano das escolas, fazem falar (e tentam produzir) certos modos específicos para relações e prazeres. Mas, de certo modo, a proibição também instiga - os assuntos proibidos, velados, que devem ser descobertos e pesquisados. As regulamentações proibitivas indicam experimentações diversas, com o objetivo de enfrentar, ou de burlar. Mais ainda, produzem novas perguntas para o espaço escolar, território da dúvida, da pesquisa e da aprendizagem.

Como transformar, então, a relação de experiência da brincadeira na construção de regras com diferentes participantes do jogo? Será possível discutir e explicitar as regras desse jogo, que envolve comportamento, convivência e, até certo ponto, disciplina?

Com relação à masturbação, a escola ainda opera na manutenção do instituído e reedita uma antiga proibição. Com isto, a escola não é inovadora, pois suas estratégias de controle da masturbação apenas mantêm o que se tem de mais forte referente a sexualidade: seus preconceitos. Mais ainda, mantém-se em um papel montado há séculos para que adultos vigiem constantemente as crianças, investiguem possíveis transgressões e evitem que fiquem sozinhas.

Repensar essa postura pode gerar espaços mais libertários e menos homogenizados destas subjetividades e dos processos de aprendizagem e construção da sexualidade. Mas, isto só é possível, se criarmos relações mais transversais com os pequenos, relações que de fato possibilitem uma infância em que possam se manifestar mais plenamente. Discussões coletivas sobre corpo, brincadeira e prazer entre educadoras e educadores, crianças e famílias podem indicar um caminho possível. Neste sentido, também precisamos dar mais espaço para as crianças e sua ludicidade, pois só assim poderemos sair do mundo adultocêntrico e marcado pelo discurso da sexualidade que ainda nos encontramos. Este mundo adultocêntrico não permite que haja outros mundos possíveis além daquele compreendido e dominado por nós.

Construir escolas que possam acolher a provisoriedade das brincadeiras, os espaços adaptados e inventados pelas crianças e construir juntos as regras dos jogos mais do que reprimir comportamentos e manifestações: um projeto em nada impossível.

\section{Referências}

AMADO, Guilherme. Um deputado na cruzada contra a masturbação.: Publicado em: 04/01/2017. Disponível em http://blogs.oglobo.globo.com/lauro-jardim/post/um-deputado-nacruzada-contra-masturbacao.html Acesso em: 9 mar. 2017 
AQUINO, Felipe. A luta contra o vício da masturbação. in: Canção Nova. Publicado em 21/8/2015. Disponível em: http://formacao.cancaonova.com/afetividade-esexualidade/dependencia-sexual/a-luta-contra-o-vicio-da-masturbacao/ Acesso em: 20 nov. 2016.

ARIÈS, Philippe. História Social da Criança e da Família. Rio de Janeiro: Zahar, 1978. BACCA, Ana Maria; PEY, Maria Oly \& SÁ, Raquel Stela. Nas pegadas de Michel Foucault: apontamentos para a pesquisa de instituições. Rio de Janeiro: Achiamé, 2004.

BENJAMIN, Walter. Reflexões sobre a criança, o brinquedo e a educação. São Paulo: Duas Cidades, Editora 34, 2009.

Magia e técnica, arte e política: ensaios sobre literatura e história da cultura. São Paulo: Brasiliense, 2012.

. A hora das crianças: narrativas radiofônicas de Walter Benjamin. Rio de Janeiro: Nau Editora, 2015.

BRASIL. Lei no 8.069 de 13 de julho de 1990. Dispõe sobre o Estatuto da Criança e do Adolescente e dá outras providências. Disponível em: http://www.planalto.gov.br/ccivil 03/leis/L8069 Acesso em: 25 fev. 2017.

Secretária de educação Fundamental. Parâmetros curriculares nacionais: orientação sexual. 1998. Disponível em: http://portal.mec.gov.br/seb/arquivos/pdf/orientacao.pdf Acessado em 25/02/2017

BROUGÈRE, Gilles. Brinquedo e cultura. São Paulo: Cortez, 2001 (Coleção questões da Nossa Época; v.43).

BUTLER, Judith. Corpos que pesam: sobre os limites discursivos do "sexo". In: LOURO, Guacira Lopes (org). O Corpo Educado: Pedagogias da sexualidade. Belo Horizonte: Autêntica, 2010, p. 151-172.

. Relatar a si mesmo: crítica da violência ética. Belo Horizonte: Autêntica,

2015.

CHAGAS, Tiago. Pastor Silas Malafaia critica pais e líderes que não falam sobre masturbação com jovens e diz: "É pecado" Publicado em 8/4/14. Disponível em: https://noticias.gospelmais.com.br/silas-malafaia-critica-pais-nao-falam-masturbacao-pecado66671.html Acesso em 20 nov. 2016.

DUBET, François. Mutações cruzadas: a escola e a cidadania. Revista Brasileira de Educação, v. 16, n. 47, mai-ago, 2011, p. 289-305.

FOUCAULT, Michel. Vigiar e Punir: nascimento da prisão. Petrópolis: Vozes. 1987. . História da Sexualidade I: A vontade de saber. São Paulo: Graal, 1988. . Em defesa da sociedade. Rio de Janeiro: Martins Fontes, 1999. Os Anormais. São Paulo: Martins Fontes, 2010.

GUIMARÃES, Isaura. Educação sexual na escola: mito e realidade. Campinas, SP,: Mercado das letras, 1995

GONDRA, José G.. Estropiados, tarados, imbecis, loucos, criminosos e incapazes: o precesso de normalização da casa e da escola em questão. in: RESENDE, Haroldo de (Org.) Michel Foucault: O governo da infância. Belo Horizonte: Autêntica, 2015.

KRAMER, Sonia. Profissionais de educação infantil: gestão e formação. São Paulo: Ática, 2005 
JOBIM E SOUZA, Solange. Re-significando a psicologia do desenvolvimento: uma contribuição crítica à pesquisa da infância. In: KRAMER, Sonia \& LEITE, Maria Isabel (orgs.) Infância: fios e desafios da pesquisa. Campinas: Papirus, 1996, p. 39-55.

LOURO, Guacira. Lopes. Um corpo estranho: ensaios sobre sexualidade e teoria queer. Belo Horizonte: Autêntica, 2004.

NASCIMENTO, Maria Livia \& CHIARADIA, Cristiana de França. A retirada da orientação sexual do currículo escolar: regulações da vida. Sisyphus Journal Of Education v. 5, n 1, 2017, pp. 101- 116, 2017. Disponível: http://revistas.rcaap.pt/sisyphus/article/view/10453/8891 Acesso em: 20 mar. 2017.

RAGO, Margareth. Foucault, o onanismo e a criança. in: RESENDE, Haroldo de (Org.) Michel Foucault: O governo da infância. Belo Horizonte: Autêntica, 2015.

VIGOTSKY, Lev Semenovich. A formação social da mente: o desenvolvimento dos processos psicológicos superiores. São Paulo: Martins Fontes, 1998.

\footnotetext{
i Psicólogo, Mestre em Psicologia, Doutorando pelo Programa de Pós-Graduação em Psicologia da Universidade Federal Fluminense (Bolsista CAPES)

ii Psicóloga, Mestre em Educação, Doutoranda pelo Programa de Pós-Graduação em Psicologia da Universidade Federal Fluminense

iii Projeto de Lei 6.449/2016 do Deputado Federal Marcelo Aguiar.” Obriga as operadoras que disponibilizam o acesso à rede mundial de computadores, criarem sistema que filtra e interrompe automaticamente na internet todos
} os conteúdos de sexo virtual, prostituição, sites pornográficos." Disponível em: http://www.camara.gov.br/proposicoesWeb/fichadetramitacao?idProposicao=2116534 Acesso em 10 mar. 2017.

iv Congresso em Foco "Deputado quer bloquear pornografia na internet para coibir masturbação" Disponível em: http://congressoemfoco.uol.com.br/noticias/deputado-quer-proibir-pornografia-na-internet-para-evitar-masturbacao/ Acessado em: 9 mar. 2017.

' Correio Braziliense "Internautas brincam e organizam 'punhetaço' contra PL anti-masturbação" Disponível em: http://www.correiobraziliense.com.br/app/noticia/brasil/2017/01/05/internas_polbraeco,563734/o-que-e-o-projetode-lei-anti-masturbacao.shtml Acessado em 10 mar. 2017.

${ }^{v i}$ De acordo com Michel Foucault (2010, p.36), em curso proferido em 1974-1975, normalização diz respeito ao "[...] funcionamento de um poder que não é nem o poder judiciário nem o poder médico, um poder de outro tipo, [...] a se constituir como instância de controle do anormal". Trata-se, portanto, do estabelecimento e regulação de quais vidas são consideradas fora das normas em conjunto com uma incessante força para adequá-las, baseada em um campo intercessor entre as ciências médicas e as práticas jurídicas.

vii Ainda que os contextos estudados tanto por Ariès quanto por Foucault sejam geográfica e historicamente diferentes do experimentado no Brasil, entendemos que estes autores investigam importantes processos de constituição da modernidade tal qual a conhecemos, diretamente relacionada ao sistema capitalista de produção, no qual estamos profundamente integrados.

viii Foucault (2010) discute longamente as normas sobre o corpo que se estabelecem no advento da modernidade; assim, brincadeiras entre crianças e adultos que entendemos como sexuais poderiam fazer parte da paisagem cotidiana sem, necessariamente, serem lidas como crime ou mesmo perigo aos infantes.

ix “Contudo, não existe nenhum 'eu' que não possa se separar totalmente das condições sociais de seu surgimento [...] O 'eu' não se separa da matriz prevalecente das normas éticas e dos referenciais morais conflituosos [...] Quando o 'eu' busca fazer um relato de si mesmo, pode começar consigo, mas descobrirá que esse 'si mesmo' já está implicado numa temporalidade social que excede suas próprias capacidades de narração; [...] Até certo ponto, as condições sociais de seu surgimento sempre desapossam o 'eu'. Essa despossessão não significa que tenhamos perdido o fundamento subjetivo da ética" (BUTLER, 2015, p.18-19). 


\footnotetext{
x “Assim como a Igreja só se dirigia às almas consideradas iguais e universais, rejeitando os "corpos" e a vida social fora do seu reino, a escola republicana só quis conhecer alunos, razões em formação, rejeitando a infância e a adolescência fora do seu domínio" (DUBET, 2011, p. 296).

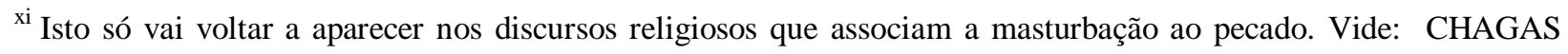
(2014) e AQUINO (2015). Ou políticos como AMADO (2017).

xii Vigotsky (1998) esclarece que a brincadeira não possibilita só prazer, também pode ser desprazeroso na medida que há atividades que podem não ser agradáveis como perder um jogo, ter de esperar sua vez de participar, não ser escolhido para um determinado grupo, não realizar corretamente uma ação, etc.
} 